\title{
The Growing Role of Big Data in Education and its Implications for Educational Leadership
}

\author{
Usama Kalim \\ Faculty of Education, Southwest University Chongqing
}

\begin{abstract}
The big data technologies in education have seen a rapid rise since the past two decades. Information intelligence has become an integral part of educational decision making. This created a trend for the strategic usage of big amount of data. New technologies have been in use for analyzing the large amount of data for making strategic decisions. This study highlights the growing importance of big data by reviewing the existing literature on big data. Furthermore using interpretive methodology this study examines the implications of big data for educational leadership. Through effective decision making by using this big data enables educational institutes to improve the process of teaching and learning. The usage of big data enables effective decision making for education by incorporating different information and communication technologies. This Big data usage in education will intensify in the near future. Educational leaders need to build different learning management system to effectively utilize the big data for decision making purposes.
\end{abstract}

Keywords: Big Data, Educational Leadership, Learning Analytics

\section{INTRODUCTION}

Qince the invention of internet every field has seen $\checkmark$ consistent transformation through the means of different advanced technologies (Drigas \& Leliopoulos, 2014). Every field is taking the advantage of modern technologies to develop further (Kalaian, Kasim, \& Kasim, 2019). The term 'big data' represent the one of the modern technology which is helping in the development of different fields (Logica \& Magdalena, 2015). The usage of Big Data for decision making has revolutionized many fields, including education. Through effective decision making by using this big data enables educational institutes to improve the process of teaching and learning. The usage of big data enables effective decision making for education by incorporating different information and communication technologies (Chae, 2019). This trend encourages educational institutions to build different learning management system to effectively utilize the big data for decision making purposes (Khan \& Alqahtani, 2020).

The trend for the development of learning management systems for handling of big data has been growing since the last few years ((ur Rehman et al., 2019).). With the introduction and rapid popularity of internet students all across the world have started using mobile phones to access online content. Their activities on the internet generate massive amount of data which can be retrieved through different technologies. This massive amount of data has the potential to be used as valuable information for making educational decision making.

The researchers are trying to define this term 'big data' in different ways (Mikalef, Pappas, Krogstie, \& Giannakos, 2018). The concept 'big data' in education represent 'to efficiently analyze this massive amount of data to produce relevant and valuable information from it' (Logica \& Magdalena, 2015). This concept has the potential to revolutionalize the way we approach the education process, by changing the means of interaction between students and teachers and by fulfilling the individual needs of learners through efficient processes (Anshari, Alas, \& Yunus, 2019).

This discussion paper is divided into two parts. In the first part, the concept of 'Big data' in education and how it is spreading worldwide along with the goals and purposes of Big Data is been discussed. The second part of this paper discusses the learning benefits and implications of Big Data for educational leaders and how this can contribute to a renowned education system.

\section{BIG DATA ROLE IN EDUCATION}

\subsection{Definition of Big Data}

In this part we will define Big Data. So, what is Big Data? "The expansion of mobile networks, cloud computing and a rise of unintelligibly of big amounts of data, are described as big Data" (Bollier \& Filestone, 2010). Beside the actual data the tools and techniques which are used to collect, analyze and inferring information from the raw data are also falls under the umbrella of big data (Yan, 2013). So, what makes Big Data or qualifies as a big data set. big are frequent explanations over time and/or space. The Web archives stores data about lots of visits from the users in a day to many web pages. The cell phone database stores the movement of its customers by checking time and position frequently, of each mobile user. Similarly for a business, the seller has thousands of stores, thousands of products, and millions of consumers and logs billions and billions of separate connections in a year (Jacobs, 2009).

As per the earlier definitions, Big Data can provide advanced parallel techniques for analysis to forecast situations which can provide information about the different activities and procedures in ways unimagined only years earlier (Bollier \& Filestone, 2010). Another aspect as Siemens and Long said, "Big Data are datasets whose size is beyond the ability of 
typical database software tools to capture, store, manage and analyze." Therefore, new techniques and technology being applied for Data-Mining and for extracting information from the raw data set (Siemens \& Long, 2011).

\subsection{Growing Size of Data}

The technologies to handle to handle big data has seen a rapid rise since the past two decades. Businesses intelligence decision making enabling large organizations to generate more profits by using the big amount of data. This created a trend for the strategic usage of big amount of data (Bollier \& Filestone, 2010). Different new technologies has been in use for analyzing the large amount of data for making beneficial inferences. As per the authors, this trend created a new concept of "knowledge infrastructure" materializing. As the author stated, database is not limited to just accounts-settling tool any more. It has been transformed into a real-time decision-making tool. In addition to that, the web is now creating new needs and requirements for information development. The information available on the web is also growing with time, as well as the number users on web (MacAfee \& Brynjolfsson, 2012). As the applications of information is spreading worldwide so the people all around the world surfing the web more and more. High quality tools like Yahoo and Google acting as an intermediary search engine to provide the required information to the user.

The size of big data can be measured in terabytes and petabytes (Herschel \& Miori, 2017). According to Reinsel, Gantz \& Rydning (2018), in 2017, there was 2.7 Zettabytes (ZB) of data online worldwide. This figure reached $4.4 \mathrm{ZB}$ in 2019 , and it is predicted that data will grow to $175 \mathrm{ZB}$ by 2025 . The amount of data available on the internet is doubling every year. Few years ago, a single terabyte of data seemed like a huge amount of data set but if it is compared with the current volume of data it looks nothing. Now, some websites even hold the data in terms of exabytes or the yottabyte, which is a trillion terabytes. From the Year 2016, each day the data about the volume of 2.5 Exabyte's has been produced by the internet and that number is doubling every 40 months or so. Now a day's more data circulate the web every second than what were once stored in the entire internet just 20 years ago. This huge difference highlights the growing volume and importance of data in the recent times.

This new dimension of data has given business and other industries a new direction to bring efficiency and effectiveness in their functions by using petabyes of data (Sivarajah, Kamal, Irani, \& Weerakkody, 2017). The source of data is not just limited from the internet there are other through which organizations are generating and collecting data. For instance, Walmart collects more than 2.5 petabytes of data every hour from the transactions of its customers. A petabyte is the equivalent of about 20 million filing cabinets' worth of text. That shows the true extent of the volume of these data. This data then be used as basis for generating reports, spot trends in the market which helps in making reasoning based decision making. Through this rational process businesses achieve their targets in the real world setting. When the volume of data becomes too big which cannot be handled and control by human mind, that's when the computer technology comes into play to make things easier (MacAfee \& Brynjolfsson, 2012).

In the recent time, data is in usage across many fields and this trend is growing with fast speed (Sin \& Muthu, 2015). There is a need for making computational theories which helps in collecting information from a large volume of data. Education is one the field which requires these theories so to better use big data for educational purposes.

The education field has grown worldwide in recent times. Data related to education has available on different platform in abundance. This huge volume of education related data has the potential to change this field for better (Yan, 2013). Educational leaders all around the world are increasingly interested in these big data to improve the quality and productivity of their educational institutions by taking the right decision based on these data. In the past, educational leaders were limited to make decisions solely based on their estimation but now these decisions can now be made on the data itself (Khan \& Alqahtani, 2020).

\subsection{Goals and Purposes of Big Data in Education}

\subsubsection{The Value of Big Data in Education}

Big Data has enabled educational leaders to make timely and effective decisions to size to improve organizational culture and student learning process (Yan, 2013). Big Data has the potential to completely change the process of education and research in the near future. In the United States a study conducted on 35 charter schools in NYC city has discovered that use of data to guide instruction was among one of the top five policies connected with significant academic effects (Picciano, 2012).

Another dimension of big data technology is cloud computing. These collaborative technologies can improve educational services like allowing access of online content cheaply to the needy students (Bughin, Chui \& Manyika, 2010). In addition, as the author stated "Big Data can support the classic educational system helping teachers to analyze what students know and what techniques are most effective for each pupil." So it also provides information to the teachers that how they can improve the learning process by changing their techniques and methodology in the classroom. Furthermore, technologies like Data mining and Data analytics provides timely feedback to students and teachers about their academic performance (West, 2012). As per the author, the technologies like these helps building education patterns which provide key information the educational leaders. For instance the educational patterns can provide information about the student's particular needs and through making effective decisions the danger of their drop out and failure can be avoidable. The author also stated that these educational 
patterns also help in developing special pedagogical approaches that works well with the particular students who has special needs.

Beside these usages Siemens and Gasevic (2012) stated in their study that Big Data has the potential to change the conventional education system to online education system. The e-learning platforms have recently gained popularity worldwide. On these platforms more and more students are joining which ultimately creating new data online. These new data, collected through different platforms, helping the educational leaders to understand the needs and new trends in education.

\subsubsection{The Effects of Big Data in Education}

Although the usage of big data in the field of education is still limited but the trend of using big data for decision making is continuously increasing (Bughin, Chui \& Manyika, 2010). The reason of this upward trend is effectiveness of data-driven decision making. This trend is predicted to grow further in the near future and educational institutions will need specialized persons who can handle large scale data and these technologies. Either educational leaders needs to get familiar to these new tools and technologies or to create a separate department or job to facilitate the data-driven decision making process. Hence we can conclude that in the coming time there will definitely be more need of Data Scientists and Data Analysts in the field of education.

\subsection{Big Data Tools and Techniques}

\section{Techniques}

The challenge of handling large volume of Big Data is done through various modern techniques. In the below part we will discuss some of the most commonly used techniques for data mining:

- Regression - This is statistical technique through which value of a dependent variable is predicted by estimating the relationship of variables.

- Nearest Neighbor - This technique predicts the value which is closest to the predicted record.

- Clustering - This technique divide data by grouping the records on the basis of some homogenous characteristics.

- Classification - This technique categorized the data on the basis of record.

- Open Source Tools: Different tools have been used for handling of big data. Some of the tolls are listed below:

- MongoDB this is a database management system for storing documents.

- Hadoop is a computer based programming model which process large volume of data in clusters.

- MapReduce this is a programming tools which helps enable processing of large volume of data in large clusters of compute nodes.
- Orange this is a computer program for mining big data.

- Weka is another computer program for handling of large volume of data. It uses algorithms for data mining.

\subsection{Applications in learning}

Big Data techniques develop different learning analytics for the field of education:

\section{Performance Prediction}

Different learning analytics helps predict Student's performance and how this performance gets affected given student's interaction in a particular learning environment with other students and teachers.

\section{Attrition Risk Detection}

Through learning analytics information can be gathered about student's behavior, with this information educational institutes can minimize the risk of students dropping out from courses.

\section{Data Visualization}

It is becoming more and more difficult to prepare and present educational reports due to the large size of data. Learning analytics help in developing different visualization methods to effectively present those trends and relations in education.

\section{Intelligent feedback}

Modern techniques also helpful for students as they can get instant feedback of their work with the help of different learning analytics. These timely responses helps students to remain motivated, informed and improve their performance.

\section{Course Recommendation learning analytics}

It provides information about different trends in education. These analytics also gives educational institutes the real picture about students interest, job market situation etc. Based on all these information educational institutes can rightly guide their students about course recommendation.

\section{Student skill estimation}

Learning Analytics also help institutions to acquired knowledge about students skills level.

\section{Behavior Detection}

Learning analytics helps educational institutes to develop a student learning based model by understanding their behavior.

\section{Grouping \& collaboration of students}

Through learning analytics educational institutions gains understanding about different groups within the students. This helps institutions to divide students into different groups for better collaborations between the students. 


\section{Planning and scheduling}

Through learning analytics educational institutes are able to predict certain things about the future. This way institution can do better planning and scheduling.

\subsection{Key works Highlighting the Significance of Big Data use in Education}

\subsubsection{Performance Prediction}

Learning analytics provides information about student's behavior based on their previous data. By understanding students behavior educational institutions can predict the performance of the students. This information then that can be used in identifying the underperforming students so that the instructors can focus more on developing them. The famous study conducted by Kellen (2013) by the title "Applying Big Data in Higher Education: A Case Study", described the successful implementation of a Big Data analysis tool: "SAP's HANA", in the University of Kentucky. In that study the author collected data about the background of the students. Based on their background the analysis tool calculated a " $\mathrm{K}$ Score". This score was then used to predict the student performance. As per the criteria set by researcher, a low Kscore indicates an underperforming student who needs more attention of the instructor in order be performing well.

\subsubsection{Skill Estimation}

Skill Estimation in educational term is used to judge the ability of students in a particular environment. The skill set of the students largely affected by the environment in which they are learning. By estimating students skills educational institutions can get better understanding about the skill set of the students and the learning environment can be adjusted accordingly in order to further enhance their skill set. Blikstein (2011) in his paper "Using learning analytics to assess students' behavior in open-ended programming tasks" analyzed student behavior by using a software "NetLogo" to predict the level of students skills. The author analyzed the student's skill level by putting student's data in a lab machine using software and predicted the student's skill level by analyzing the error rate and progress rate. Another important study related to students skills assessment was done by Beheshti and Desmarais (2014), by the title "Predictive performance of prevailing approaches to skills assessment techniques: Insights from real vs. synthetic data sets". In that study the author used real data vs. synthetic data sets for assessing the skills of students. The author predicted skill set of students using both data sets and concluded that real data provide better estimation for assessing student skill level.

\subsubsection{Behavior Detection}

For understanding the effects of a particular lesson on student behavior Grafsgaard (2014) introduced a system for recognizing student behavior in the classroom through their facial expressions. In his study, "Predicting Learning and Affect from Multimodal Data Streams in Task-Oriented
Tutorial Dialogue", he introduced a system for understanding lesson learning outcome by recognizing the facial expressions of the students. By judging students expressions, one can predict learning outcomes of the students. The author also used different gesture detection and posture tracking algorithms to understand the students non-verbal behaviors which are connected to students learning. In another study by Seong Jae Lee (2014), the author described a framework for understanding and modeling students behavior. In his paper, "Learning Individual Behavior in an Educational Game: A Data-Driven Approach" he stated that by modeling student behavior in response to certain type of activities gives a better picture of students behavior.

\subsubsection{Attrition Risk Prediction}

The big data techniques have been used by the researchers to predict the attrition risk of students. Students dropping out from the courses has been a problem for educational institutions. To minimize this risk of dropping out from courses, educational institutions need to understand and predict students behavior. Big data is helpful in predicting students behavior as Lalitha Agnohotri, in her study "Building a Student At Risk Model: An End-to-End Perspective From User to Data Scientist", calculated the attrition risk level "Students at Risk" by using historical data to model the students behavior. The model provided different attrition risk level "Risk Ratings" of the students. The author stated that, by using those rating system educational institutions can predict about the student behavior and will be able to apply needed measures to retain those students in advance.

\subsubsection{Data Visualization}

Kellen (2013) conducted famous study about data visualization in education. The data about the students was collected through monitoring their regular activities inside classroom. With this obtained data different patterns about their behavior were been observed. The visualization of this observational data clearly indicated the patterns of the data that can be easily recognized. This method of visualization was proved to be more effective for collecting data then traditional way of reporting the data. The author stated that, through this visualization technique institution can collect valuable information about student's behavior in the classroom more efficiently and effectively.

\section{BIG DATA IMPLICATIONS FOR EDUCATIONAL LEADERS}

\subsection{Learning Benefits}

Big data opens doors of learning for education leaders. To effectively apply data-driven decisions in the educational environment educational leaders needs to get familiar to these new tools and technologies. As the big data mostly comes from technology-based learning platforms. In this case the analytics can improve educational leaders ability to be more effective in research and help them to be more efficient (Falakmasir \& Habibi, 2010). It also has positive effect on the 
student learning side. As students are using these platform so they are having more opportunities for new learning experiences. Students can share information with each other and with educational institutions to learn and expand their knowledge. Educational institutes and can use these data to solve education related problems and prepare for future (Falakmasir \& Habibi, 2010).

\subsection{Efficiency and Effectiveness in Decision Making}

Decision making is complex matter even on individual level or in group level. Decision making is a dynamic process where leaders has to make different types of decision i.e. major and minor decisions, programmed and nonprogrammer, Strategic and tactical or operational decisions, simple and complex, individual and group decisions. The sole purpose of all these decision making is to select the best alternatives from the circumstances and improve the effectiveness and efficiency of the organization. 'Big Data' concept has the potential to revolutionalize the way we approach the education process, by changing the means of interaction between students and teachers and by fulfilling the individual needs of learners through efficient processes. For Educational leaders 'Big data' used as a valuable information system for making educational decision making. The can bring efficiency and effectiveness in the educational leaders decision making (Logica \& Magdalena, 2015).

There are numerous advantages educational leader gets while using 'Big Data' for decision making (Logica \& Magdalena, 2015). Below are some of the Decision Making advantages of big data for Educational leaders.

- Efficiency in managerial function: For administration decisions making is playing the role of back bone, without all the functions of an Educational institution cannot be operated properly. Big data provides timely information for decision making. This brings efficiency in the managerial function of leaders.

- Helpful in planning and policies: For establishing any plan the important thing to take is the decision first. Big data provides a true analysis of the past and can also be used for predicting future. With lots of information available to educational leaders it improves planning and policies matters of any educational organization.

- $\quad$ Time Savings: In the competitive world choosing the right alternatives on time is very important for any organization success. As Big data helps educational leaders in variety of ways and bring effectiveness and efficiency in the operations of an educational institution. So it is playing a vital role in the success of educational organization.

\section{CONCLUSION}

As we can see from the discussion of above chapters, 'Big Data' has a very significant role in education. The uses of big data techniques are helping educational leaders to make the right and timely decisions. Big data has the potential to shape a modern and dynamic education system. In the new era of 'Big Data' the educational leaders will not have the traditional difficulties related to decision making. They will be able to make more timely and accurate decisions. But to efficiently utilize the benefits of Big Data, the educational leaders must have to cope up with learning the new technologies related to big data. Furthermore, through effective decision making by using this big data enables educational leaders improve the process of teaching and learning. The usage of big data enables effective decision making for education by incorporating different information and communication technologies. In future, this trend will create more demand for educational institutions to build more learning management system to effectively utilize the big data for decision making purposes.

\section{REFERENCES}

[1] Agnihotri, L., \& Ott, A. (2014, July). Building a student at-risk model: An end-to-end perspective from user to data scientist. Proceedings of the 7th International Conference on Educational Data Mining, pp. 202-212.

[2] Anshari, M., Alas, Y., \& Yunus, N. (2019). A survey study of smart phones behavior in Brunei: A proposal of Modelling big data strategies. In Multigenerational Online Behavior and Media Use: Concepts, Methodologies, Tools, and Applications, (pp. 201214). IGI global.

[3] Beheshti, B., \& Desmarais, M. (2014, July). Predictive performance of prevailing approaches to skills assessment techniques: Insights from real vs. synthetic data sets. In Educational Data Mining 2014. Proceedings of the 7th International Conference on Educational Data Mining, pp. 409410.

[4] Bollier, D., \& Firestone, C. M. (2010). The promise and peril of big data (pp. 1-66). Washington, DC: Aspen Institute, Communications and Society Program.

[5] Brown, B., Chui, M., \& Manyika, J. (2011). Are you ready for the era of "big data"? Report, McKinsey Global Institute. October, San Francisco, CA. vol. 4, 24-35.

[6] Bughin, J., Chui, M., \& Manyika, J. (2010). Clouds, big data, and smart assets: Ten tech-enabled business trends to watch. McKinsey quarterly, 56(1), 75-86.

[7] Chae, B. K. (2019). A general framework for studying the evolution of the digital innovation ecosystem: The case of big data. International Journal of Information Management, 45(1), 83-94.

[8] DeMarco, A. L. (2018). The relationship between distributive leadership, school culture, and teacher self-efficacy at the middle school level.

[9] Drigas, A. S., \& Leliopoulos, P. (2014). The use of big data in education. International Journal of Computer Science Issues (IJCSI), 11(5), 58-66.

[10] Gento, S., Huber, G. L., González, R., Palomares, A., \& Orden, V. J. (2015). Promoting the quality of educational institutions by enhancing educational leadership. US-China Education Review, 5(4), 215-232.

[11] Grafsgaard, J., Wiggins, J., Boyer, K. E., Wiebe, E., \& Lester, J. (2014, July). Predicting learning and affect from multimodal data streams in task-oriented tutorial dialogue. In Educational Data Mining 2014. Proceedings of the 7th International Conference on Educational Data Mining.

[12] Herschel, R., \& Miori, V. M. (2017). Ethics \& big data. Technology in Society, 49(4), 31-36.

[13] Jacobs, A. (2009). The pathologies of big data. Communications of the ACM, 52(8), 36-44. 
[14] Kalaian, S. A., Kasim, R. M., \& Kasim, N. R. (2019). Descriptive and predictive analytical methods for big data. In Web Services: Concepts, Methodologies, Tools, and Applications, (pp. 314-331). USA: IGI global. https://doi.org/10.4018/978-1-5225-7501-6. ch018.

[15] Kellen, V., Recktenwald, A., \& Burr, S. (2013). Applying Big Data in higher education: A case study. Cutter Consortium white paper, 13(8), 1-39.

[16] Khan, S., \& Alqahtani, S. (2020). Big Data Application and its Impact on Education. International Journal of Emerging Technologies in Learning (iJET), 15(17), 36-46.

[17] Leithwood, K. A., \& Riehl, C. (2003). What we know about successful school leadership. Nottingham: National College for School Leadership.

[18] Leithwood, K., Patten, S., \& Jantzi, D. (2010). Testing a conception of how school leadership influences student learning. Educational Administration Quarterly, 46(5), 671-706.

[19] Logica, B., \& Magdalena, R. (2015). Using big data in the academic environment. Procedia Economics and Finance, 33(4), 277-286.

[20] Manyika, J., Chui, M., Brown, B., Bughin, J., Dobbs, R., Roxburgh, C., \& Hung Byers, A. (2011). Big data: The next frontier for innovation, competition, and productivity. McKinsey Global Institute.

[21] McAfee, A., Brynjolfsson, E., Davenport, T. H., Patil, D. J., \& Barton, D. (2012). Big data: the management revolution. Harvard business review, 90(10), 60-68.

[22] Mikalef, P., Pappas, I. O., Krogstie, J., \& Giannakos, M. (2018). Big data analytics capabilities: A systematic literature review and research agenda. Information Systems and e-Business Management, 16(3), 547-578.

[23] Mohammad Hassan Falakmasir and Jafar Habibi, "Using educational data mining methods to study the impact of virtual classroom in e-learning", Proceedings of the $3^{\text {rd }}$ International Conference on Educational Data Mining, pp. 241- 248, 2010.

[24] Mulford, B. \& Silins, H. (2003). Leadership for organisational learning and student outcome-What do we know? Cambridge Journal of Education, 33(2), 175-195.
[25] Northhouse, P. G. (2013). Leadership: Theory and Practice (6th ed.). New Delhi: Sage Publications India Private Limited.

[26] Paulo Blikstein, "Using learning analytics to assess students' behavior in open-ended programming tasks", Proceedings of the 1st International Conference on Learning Analytics and Knowledge, pp. 110-116, 2011.

[27] Picciano, A. G. (2012). The evolution of big data and learning analytics in American higher education. Journal of asynchronous learning networks, 16(3), 9-20.

[28] Seong Jae Lee, Yun-En Liu and Zoran Popovic, "Learning Individual Behavior in an Educational Game: A Data Driven Approach", Proceedings of the 7th International Conference on Educational Data Mining, 2014.

[29] Sergiovanni, T. J. (2004). What's in it for schools? Abingdon, Oxon: Routledge Falmer.

[30] Siemens, G., \& Gasevic, D. (2012). Guest editorial-learning and knowledge analytics. Journal of Educational Technology \& Society, 15(3), 1-2.

[31] Siemens, G., \& Long, P. (2011). Penetrating the fog: Analytics in learning and education. EDUCAUSE review, 46(5), 30-36.

[32] Sin, K., \& Muthu, L. (2015). Applicaion of Big Data in education data minng and learning analytics. ICTACT journal on soft computing, 5(4), 1035-1049.

[33] Sivarajah, U., Kamal, M. M., Irani, Z., \& Weerakkody, V. (2017). Critical analysis of big data challenges and analytical methods. Journal of Business Research, 70(2), 263-286.

[34] Ur Rehman, M. H., Yaqoob, I., Salah, K., Imran, M., Jayaraman, P. P., \& Perera, C. (2019). The role of big data analytics in industrial internet of things. Future Generation Computer Systems, 92(2), 578-588.

[35] West, D. M. (2012). Big data for education: Data mining, data analytics, and web dashboards. Governance studies at Brookings, 4(1), 1-10.

[36] Wrigley, T. (2006). Another school is possible. London: Bookmarks.

[37] Yan, J. (2013). Big data, Bigger opportunities. White Paper, April, 9. 